\title{
Clinimetric scale to measure surgeons' satisfaction with anesthesia services
}

\author{
Sylvie Le May RN MSc, * \\ Gilles Dupuis PhD, $\dagger$ \\ François Harel MSc, $\ddagger$ \\ Marie-Christine Taillefer BSc, $\uparrow$ \\ Serge Dubé MD MSc,, $\mathbb{S}$ \\ Jean-François Hardy MD*
}

Purpose: Continuous quality improvement is of increasing interest to anesthesiologists. Since surgeons are coworkers and important clients of anesthesiologists, the level of satisfaction of surgeons with anesthesia services should be explored to optimize quality. The purpose of this study was, first, to introduce the concept of surgeons as clients of anesthesiologists and second, to develop and test an instrument to measure surgeons' satisfaction, the Surgeon Satisfaction with Anesthesia Services (SSAS) scale.

Methods: A conceptual model of surgeon satisfaction with anesthesia services was created before the development of the SSAS scale. The scale, composed of socio-demographic, Likert-type and open-ended questions was sent to a sample of 250 surgeons selected randomly by the Collège des Médecins du Québec. Exploratory factorial analysis were performed on the results.

Results: A Cronbach's alpha of 0.84 was obtained for internal consistency. Exploratory factorial analysis yielded two subscale factors: a) clinical expertise and b) attitudes and behaviour. Global mean of surgeons'satisfaction was moderately high (3.1 I/4.0). Satisfaction was not related to sociodemographic variables. Very high scores were obtained for items related to clinical expertise. Items related to attitudes and behaviour obtained lower scores. A significant difference was obtained between both factors $(t=-5.732, P=0.000 \mathrm{I})$.

Conclusion: The SSAS scale is a new instrument to evaluate surgeon satisfaction. Overall, surgeons seem satisfied with anesthesia services, but many areas of dissatisfaction persist. Further discussions with surgeons should be encouraged, in view of improving the perceptions of the quality of anesthesia services and interprofessional relationships.

Objectif : L'amélioration continue de la qualité comprend la perception des clientèles d'un service. Puisque les chirurgiens font partie des principaux clients des anesthésiologistes, il devient important d'explorer leurs perceptions en regard des services anesthésiques. Notre objectif est d'introduire le concept des chirurgiens en tant que clients des anesthésiologistes puis de vérifier les attributs de l'Échelle de Satisfaction des Chirurgiens en regard des Services Anesthésiques (ESCA).

Méthode : Un modèle sur la satisfaction des chirurgiens en regard des services anesthésiques a été créé préalablement à l'ESCA. L'ESCA comprend des questions de type Likert, ouvertes et sociodémographiques. Cet instrument a été envoyé à un échantillon de 250 chirurgiens sélectionnés de façon aléatoire par le Collège des Médecins du Québec.

Résultats : Un alpha de Cronbach de 0,84 a été obtenu pour l'ESCA. L'analyse factorielle exploratoire a identifié deux facteurs : a) expertise clinique et b) attitudes et comportement. La moyenne générale de la satisfaction des chirurgiens était modérément élevée $(3,1$ / /4,0). Aucun des facteurs sociodémographiques ne s'est révélé significatif en regard de la satisfaction. Des scores élevés ont été obtenus sur les items reliés à l'expertise clinique. Les items reliés aux attitudes et comportements ont obtenu des scores plus faibles. Une différence significative a été obtenue entre les deux facteurs $(t=-5,732, P=0,000 \mathrm{I})$.

Conclusion : L'ESCA est un nouvel instrument pour évaluer la satisfaction des chirurgiens. Les chirurgiens de l'étude sont satisfaits des services anesthésiques mais plusieurs insatisfactions demeurent. Ces informations devraient être utilisées afin de favoriser les discussions avec les chirurgiens et d'améliorer la qualité des services anesthésiques.

From the Departments of Anesthesiology, ${ }^{*}$ and Biostatistics, $\ddagger$ Montreal Heart Institute, Department of Psychology, $†$ Université du Québec à Montréal, and Department of Surgery, $\$$ Maisonneuve-Rosemont Hospital, Montreal.

Address correspondence to: Dr. Jean-François Hardy, Montreal Heart Institute, 5000 Bélanger Est, Montréal, Québec, HIT 1C8

Canada. E-mail: jean-francois.hardy@umontreal.ca

This study was supported in part by the Department of Anesthesiology, Montreal Heart Institute, Montreal, Canada.

Accepted for publication December 19, 1999.

CAN J ANESTH 2000 / 47: 5 / pp 398-405 


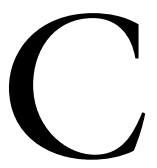

ONTINUOUS Quality Improvement (CQI) is of increasing interest to anesthesiologists. Since surgeons are one of their important clients along with patients, students and hospital administration, it is important for anesthesiologists to include the level of satisfaction of surgeons regarding anesthesia services in their CQI efforts. The concept of surgeons as part of the clientele of anesthesiologists is new and unfamiliar, and many anesthesiologists are still sceptical towards considering surgeons as their customers. Nevertheless, several authors strongly believe that, since the department of anesthesia offers essential services to the department of surgery, the latter are then considered clients (internal customers) of the former. ${ }^{1,2}$

Review of the literature through data banks such as Medline, Current Contents, Dissertation Abstracts, Psyclit, from 1980 to February 1999, using the keywords: surgeon satisfaction, surgeon perceptions, surgeon \& anesthetist, interprofessional relationships, and interdisciplinary, yielded only one study concerning the evaluation of surgeons' satisfaction with anesthesia services. ${ }^{3}$

The purpose of this article is twofold: first, to introduce the concept of surgeons as clients of anesthesiologists and second, to present the results of a study designed to develop and test a novel instrument to measure surgeons' satisfaction, the Surgeon Satisfaction with Anesthesia Services (SSAS) scale.

The concept: surgeons as clients

We first define the concept of surgeons as clients of anesthesiologists, as the perceptions of surgeons concerning the anesthesiologists' success in meeting their expectations regarding communication, interpersonal relationships, exchanges and clinical services provided by anesthesiologists. We termed this concept «Surgeon Satisfaction with Anesthesia Services». Figure 1 shows this concept in the form of a model of surgeon satisfaction with anesthesia services. We were influenced by the model of Lee \& $\mathrm{Lum}^{4}$ adapted from Iezzoni, ${ }^{5}$ to elaborate the SASS model. The figure shows the different relationships between the elements that may influence surgeon satisfaction with anesthesia services. The model presents elements related to anesthesiologist characteristics per se (Clinical expertise, Attitudes \& Behaviour and Personality), as well as external elements, related to the provision of anesthesia services (number of anesthesiologists, mode of remuneration, etc.). All of these elements combined with the interactions with surgeons, may explain surgeons' satisfaction or lack thereof. This model constitutes our conceptual repre- sentation of the variables possibly related to surgeons' satisfaction with anesthesia services. It will require empirical validation to strengthen and verify the elements and relationships presented, but we suggest it constitutes a reasonable initial approach to study surgeon satisfaction.

\section{Methods}

\section{Development of the SSAS scale}

The principal stages in the development of the SSAS scale are shown in Figure 2. The items of the scale were first taken from the literature ${ }^{2}$ and from suggestions of authors. The format of the scale was inspired from the Interprofessional Perception Scale. ${ }^{6}$ A preliminary version of the scale was submitted to an anesthesiologist and an expert in psychometry for a first content validation. Following suggestions from this first validation, a second content validation was performed with three surgeons from different specialties. This led to the first version of the Surgeon Satisfaction with Anesthesia Services (SSAS) scale. At that stage, the scale was composed of 17 Likert-type questions with four levels (Strongly disagree, Disagree, Agree, Strongly agree) and four open-ended questions. Some of the questions $(5,8,12,13,15,17)$ are negatively worded (reversed) to control for the occurrence of a bias of acquiescence (Tendency to give positive responses to a question irrespectively of the content of the item). ${ }^{7}$

This initial version was tested with five cardiac surgeons (convenience sample). Comments from these surgeons led to multiple corrections and elaboration of a subsequent version of the scale. This last version included questions related to sociodemographic and professional variables, 17 Likert-type questions and two open-ended questions exploring surgeon satisfaction: 1) Are you satisfied with the interactions you have with the anesthesiologists outside of the operating room?, 2) What do you think would improve the quality of services provided by anesthesiologists to your department of surgery?

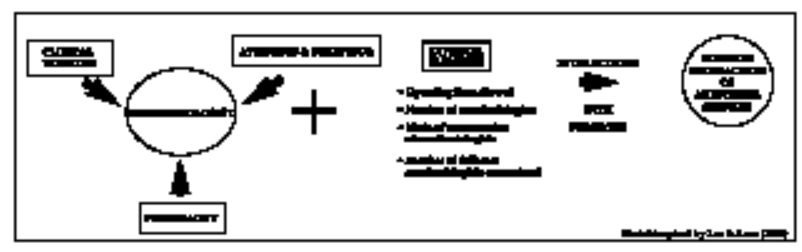

FIGURE 1 The model of surgeon satisfaction with anesthesia services. Characteristics of the anesthesiologists such as clinical expertise, attitudes \& behaviour and personality traits combined to external elements and interactions with surgeons, might explain surgeon satisfaction regarding anesthesia services. 


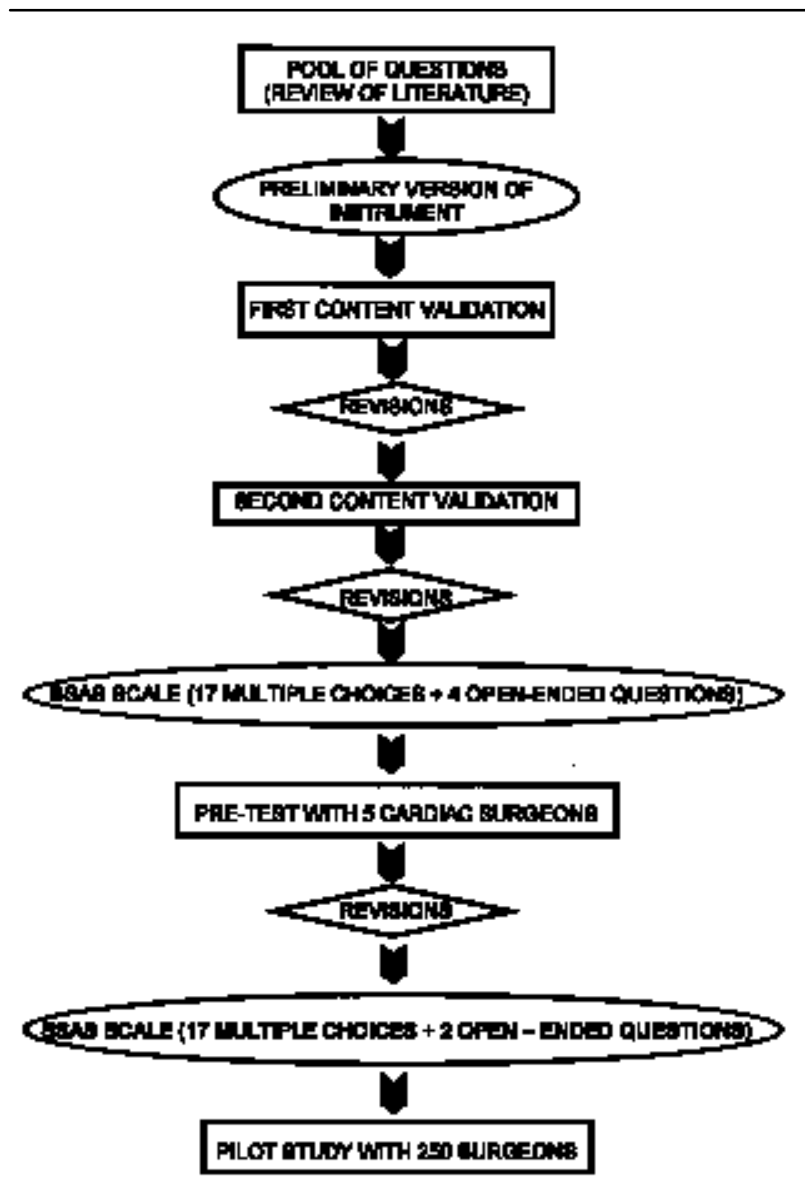

FIGURE 2 Principal stages in the development of the SSAS scale. Rectangles represent the different phases towards the validation of the SSAS scale. Lozenges represent changes made to the SSAS scale following comments of reviewers. Ellipses represent different versions of the SSAS scale.

Appendix 1 presents a translated version of the SSAS scale. The English version was verified using a back-to-back translation method (French $\rightarrow$ English then, English $\rightarrow$ French) by two surgeons and three anesthesiologists.

\section{Data collection}

A sample of 250 French speaking surgeons, selected at random, across the province of Quebec, Canada, was obtained from the Collège des Médecins du Québec. A covering letter, the SSAS scale and a stamped return envelope were sent to all surgeons of the sample during the period of January 1998 to March 1998. The questionnaires were coded only to facilitate the inventory of the returned questionnaires. A second mailing was undertaken during the month of April 1998 to all non-respondents (140) from the first mailing.

\section{Statistical analysis}

Responses to each item were summarized with descriptive statistics (mean $\pm \mathrm{SD}$ ) or the percentage of surgeons who agreed/disagreed (strongly or not) whenever appropriate. The reliability (internal consistency) of the SSAS and its subscales was measured with Cronbach's Alpha. Relationships between sociodemographic, professional variables and surgeons' global satisfaction score were assessed with Pearson's correlation coefficients or one-way analyses of variance depending on the nature of the variables. Analyses were performed by using the SAS release 6.12 software (SAS Institute, Cary, North Carolina).

We also proceeded to an exploratory factor analysis of the items, based on the intercorrelation matrix. An exploratory procedure was chosen since no theoretical expectations were formulated beforehand as to the number or nature of underlying factors.

Factor analysis is a procedure essential to the development of an instrument. It serves several purposes. It helps to determine how many latent variables underlie a set of items and whether one or several more specific constructs are needed to characterize the item set. ${ }^{8}$ This is accomplished by identifying groups of items that covary with one another and appear to define meaningful underlying factors.

Factor analysis includes three stages: 1) Factor extraction (e.g. Scree test), 2) Factor rotation (e.g. Varimax rotation), 3) Factor loadings. Factor extraction determines the number of underlying factors. The goal of factor rotation is to maximize the variance of factor loadings by making high loadings (item to factor correlations) higher and low ones lower for each factor. ${ }^{8}$ Factor loadings represents the mathematical results of the correlations between the items and the number of underlying factors. ${ }^{9}$ In other words, they represent the variance expressed by each item on each factor.

Results

Sample characteristics

The overall return rate was $60 \%(150 / 250)$, including a return rate of $28 \%(40 / 140)$ from the second mailing. Of the 150 respondents, 12 declined to answer the SSAS scale but answered the sociodemographic and professional questions. The main reasons mentioned for not answering the SSAS were: retirement and administrative tasks.

The mean age of respondents was $48.5 \mathrm{yr}$ and there was a majority of men $(84.6 \%)$ over women $(15.4 \%)$. Respondents were general surgeons $(23.9 \%)$, obstetricians \& gynecologists $(20.3 \%)$ cardiovascular \& thoracic surgeons $(10.1 \%)$, otorhinolaryngologists $(8.7 \%)$, orthopedic surgeons $(8.0 \%)$, urologists $(7.2 \%)$, oph- 
TABLE I Distribution of items according to anesthesiologist factors

A) Clinical Expertise (Factor 1)

1) Maintain patients hemodynamically stable during surgery

2) Communicate with surgeons during surgery

7) Remain calm during emergencies

9) Control patients postoperative pain effectively

10) Control mechanical ventilation effectively in the postoperative period

11) Remain sufficiently present in the operating room during surgery to supervise the patient's condition and the devices installed

14) Act effectively during emergencies

B) Attitudes \& Behaviour (Factor 2)

3) Are open to criticism and constructive comments

4) Position patients and induce anesthesia rapidly

5) Encroach on my field of expertise

6) Consider my professional opinion

8) Show a passive and indifferent attitude while discussing with surgeons

13) Show a defensive attitude during discussions

16) Are punctual

17) Are not very likely to adjust their availability according to the surgeon's or patient's needs

Questions 12 and 15 obtained low variance on both factors and will be deleted from the next version of the SSAS scale.

12) Neglect to update their clinical knowledge/skills

15) Ask too many unnecessary preoperative tests

thalmologists $(6.5 \%)$, plastic surgeons $(5.8 \%)$ and neurosurgeons $(2.2 \%)$. Each of the following specialists: vascular, pediatric, gynecology/oncology and oncology surgeons accounted for $1.4 \%$ of the sample. Regarding experience, $19 \%$ had five to nine years, $13.1 \%$ had 10 to $14 \mathrm{yr}$ and $26.3 \%$ had 15 to $19 \mathrm{yr}$ of surgical experience. Twenty-seven percent had over $20 \mathrm{yr}$ of experience. Surgeons performed $9 \pm 6$ operations per week and encountered $3 \pm 1$ anesthesiologists per week on average (Distribution normally distributed).

\section{Psychometric results of the SSAS scale}

Cronbach's Alpha for internal consistency was 0.84 . Factor rotation (Varimax) determined the existence of two differentiated factors: A) Clinical Expertise (Cronbach's Alpha: 0.79), B) Attitudes \& Behaviour (Cronbach's Alpha: 0.81). A significant difference was obtained between both factors $(\mathrm{t}=-5.732, P=0.0001)$. Table I presents the distribution of the items (questions) according to both factors. Factor loadings from principal components analysis of the SSAS scale (construct validity testing) are given in Table II. Items 12 and 15 displayed the weakest distinctions between factors.

\section{Likert-type questions}

For the 17 statements of the SSAS scale, mean satisfaction averaged $3.11 / 4.0 \pm 0.37$. Table III presents the results obtained for each question, expressed in percentages and dichotomized between low ( $1=$ Disagree strongly$2=$ Disagree $)$ and high ( $3=$ Agree-4=Agree strongly) scores and also the mean score obtained for each question. The respondents scored highly (over 80\% Agree-Strongly agree ) on questions related to patient surveillance (Q-1), attitude in emergency situations (Q-6), consideration for surgeons' professional opinions (Q-7), mechanical ventilation (Q-10), and efficacy in emergencies (Q-14). Anesthesiologists also obtained high scores on the following questions: respect of surgeons' expertise (Q-5), attitude during discussions (Q-8), update of knowledge and skills (Q-12) and appropriateness of preoperative testing (Q-15). However, more than $40 \%$ of the surgeons thought that the anesthesiologists should strongly improve on the followings: openness to criticism and constructive comments $(\mathrm{Q}-3)$, rapidity in positioning and induction of patients $(\mathrm{Q}-4)$, punctuality $(\mathrm{Q}-16)$ and flexibility in adjustment of schedules to the surgeons' or patients' needs (Q-17).

Among all the sociodemographic and professional variables, only the number of different anesthesiologists encountered per week in the O.R. was correlated with the surgeons' global satisfaction score $r=-0.2 P$ $=0.0234)$.

\section{Open-ended questions}

The surgeons were offered the opportunity to express themselves, on topics covered or not by the Likert-type questions, through the open-ended questions (subjective data). Almost all (133/138) chose to comment on their relationships with anesthesiologists and/or to make suggestions to improve the quality of anesthesia services.

In general, surgeons mentioned that they would like more scientific discussions and interdepartmental meetings with anesthesiologists. They would also prefer a more personalized evaluation of patients' postoperative pain and the elimination of pain protocols.

Furthermore, they offered suggestions for the improvement of the quality of services offered by anesthesiologists: increase the number of staff anesthesiologists, improve the availability of anesthesiologists, abolish the pooling of revenues, position patients and proceed with induction more rapidly to decrease delay between cases, increase cooperation regarding priority of cases and emergency surgical procedures (necessity of an OR coordinator-not a nurse). They also suggested that the staff anesthesiologists be more patient-minded even though they do not have their own clientele, and that they should remain in the OR during the entire procedure. 
TABLE II Factor loading of items on SSAS scale

\begin{tabular}{|c|c|c|c|}
\hline & ITEMS & FACTOR 1 & FACTOR 2 \\
\hline$\overline{1)}$ & Maintain patients hemodynamically stable during surgery & 0.75 & 0.07 \\
\hline 2) & Communicate with surgeons during surgery & 0.53 & 0.11 \\
\hline 3) & Are open to criticism and constructive comments & 0.38 & 0.54 \\
\hline 4) & Position patients and induce anesthesia rapidly & 0.27 & 0.60 \\
\hline 5) & Encroach on my field of expertise & -0.02 & 0.60 \\
\hline 6) & Consider my professional opinion & 0.34 & 0.62 \\
\hline 7) & Remain calm during emergencies & 0.63 & 0.25 \\
\hline 8) & Show a passive and indifferent attitude while discussing with surgeons & 0.01 & 0.74 \\
\hline 9) & Control patients' postoperative pain effectively & 0.74 & -0.03 \\
\hline 10) & Control mechanical ventilation effectively in the postoperative period & 0.72 & 0.16 \\
\hline 11$)$ & $\begin{array}{l}\text { Remain sufficiently present in the operating room during surgery to } \\
\text { supervise the patient's condition and the devices installed }\end{array}$ & 0.57 & 0.31 \\
\hline 12) & Neglect to update their clinical knowledge/skills & 0.13 & 0.12 \\
\hline 13) & Show a defensive attitude during discussions & 0.06 & 0.74 \\
\hline 14) & Act effectively during emergencies & 0.74 & 0.15 \\
\hline 15$)$ & Ask too many unnecessary preoperative tests & 0.13 & 0.40 \\
\hline 16) & Are punctual & 0.27 & 0.56 \\
\hline 17) & Are not very likely to adjust their availability according to the surgeon's or patients' needs & 0.09 & 0.55 \\
\hline
\end{tabular}

TABLE III Responses to Likert questions of SSAS

\begin{tabular}{|c|c|c|c|c|}
\hline \multicolumn{2}{|c|}{ Questions of SSAS scale } & \multirow{2}{*}{$\begin{array}{l}\text { \% of responses } \\
(1-2)\end{array}$} & \multirow{2}{*}{$\begin{array}{l}\text { \% of responses } \\
(3-4)\end{array}$} & \multirow{2}{*}{$\begin{array}{l}\text { Mean score } \\
(\min 1.0 \text {-max } 4.0) \\
\pm S D^{*} \\
3.66 \pm 0.59\end{array}$} \\
\hline 1) & Maintain patients hemodynamically stable during surgery & & & \\
\hline 2) & Communicate with surgeons during surgery & 20.4 & 79.6 & $3.16 \pm 0.83$ \\
\hline 3) & Are open to criticism and constructive comments & 41.6 & 58.2 & $2.70 \pm 0.89$ \\
\hline 4) & Position patients and induce anesthesia rapidly & 42.3 & 57.7 & $2.55 \pm 0.95$ \\
\hline 5) & Encroach on my field of expertise (Reversed) & 94.0 & 6.0 & $1.19 \pm 0.53$ \\
\hline 6) & Consider my professionnal opinion & 12.4 & 87.6 & $3.23 \pm 0.74$ \\
\hline 7) & Remain calm during emergencies & 13.1 & 86.9 & $3.30 \pm 0.73$ \\
\hline 8) & $\begin{array}{l}\text { Show a passive and indifferent attitude while discussing with } \\
\text { surgeons (Reversed) }\end{array}$ & 89.6 & 10.4 & $1.36 \pm 0.71$ \\
\hline 9) & Control patients postoperative pain effectively & 26.1 & 73.9 & $3.09 \pm 0.95$ \\
\hline 10) & Control mechanical ventilation effectively in the postoperative period & 7.5 & 92.5 & $3.50 \pm 0.72$ \\
\hline 11) & $\begin{array}{l}\text { Remain sufficiently present in the operating room during surgery } \\
\text { to supervise the patient's condition and the devices installed }\end{array}$ & 39.4 & 61.6 & $2.74 \pm 1.05$ \\
\hline 12) & Neglect to update their clinical knowledge/skills (Reversed) & 94.4 & 5.1 & $1.22 \pm 0.61$ \\
\hline 13) & Show a defensive attitude during discussions (Reversed) & 78.8 & 21.2 & $1.64 \pm 0.94$ \\
\hline 14) & Act effectively during emergencies & 7.3 & 92.7 & $3.53 \pm 0.65$ \\
\hline 15) & Ask too many unnecessary preoperative tests (Reversed) & 91.9 & 8.1 & $1.35 \pm 0.67$ \\
\hline 16) & Are punctual & 40.1 & 59.9 & $2.75 \pm 0.95$ \\
\hline 17) & $\begin{array}{l}\text { Are not very likely to adjust their availability according to the } \\
\text { surgeon's or patient's needs (Reversed) }\end{array}$ & 54.0 & 46.0 & $2.34 \pm 1.15$ \\
\hline
\end{tabular}

* Sample normally distributed

Discussion

\section{The SSAS scale}

Internal consistency of the scale (Cronbach's Alpha) was sufficiently high to support reliability of the instrument. With respect to construct validity of the SSAS, factor analysis clearly identified two factors (clinical expertise and attitudes \& behaviour) within the SSAS. Items distributed themselves between both factors with the exception of items 12 and 15. These items obtained low variances on both factors, meaning that they do not discriminate between the dissatisfied and the satisfied surgeons. They will be removed in the next version of the instrument since they did not generate much variance. 
Establishing content validity, internal consistency and construct validity are considered sufficient psychometric measures, for a first trial, to appreciate the properties of the SSAS scale. ${ }^{9}$ It is considered inappropriate to try to perform every psychometric test available on a new scale in a single study. ${ }^{9}$ Achievement of the complete psychometric profile of a new scale takes time and many trials. ${ }^{10}$ The task of maintaining reliability and validity of instruments is never finished. Measurement devices are nearly always subject to the effects of social context. Values and practice patterns change, individuals think differently about a number of matters, and terminologies go out of fashion. ${ }^{10}$ Scale development has no end-stage, it is a continuous and retroactive process. Nevertheless, according to Crocker and Algina, ${ }^{9}$ the results attained in this study are sufficient to consider the scale proper and reliable to be employed on a departmental basis.

\section{Surgeon satisfaction}

Our study is innovative since it concerns a matter often considered problematic by anesthesiologists but seldom brought to open discussion. Since anesthesiologists and surgeons are interdependent in their work, it is important to allow more consideration to the improvement of their relationships.

The SSAS scale was developed as a means for anesthesiologists to identify areas needing improvement, to offer a better service to one of their "customers». Investigating surgeons' opinions does not mean that anesthesiologists are stepping backwards into a subservient role with surgeons. As mentioned by Duncan $^{1}$ : «Our customers want to get value for their money, and will support a specialty that visibly seeks to improve the worth of its collective practice».

Overall, our results suggest that surgeons are satisfied with the services provided by anesthesiologists but some areas remain unsatisfied. Firstly, they would like to increase their scientific and interpersonal exchanges with anesthesiologists. There is also an obvious interest by surgeons to increase productivity and since they mostly depend on anesthesiologists to do so, they want them to be available at all times.

Anesthesiologists often ask why they should care about surgeons' opinions, arguing that it would not have an impact on the distribution of their services to patients. This may not be true. When anesthesiologists meet and exceed their customers' expectations, they are and will be recognized for the quality of their practice. Excellence in performance can only be assessed by those receiving the service. It is the customers' view of the practice of anesthesiologists, not just peer review, that decides the worth of anesthesiologists to the medical system. ${ }^{1}$ Identification of areas of dissatisfaction should generate an interest to ameliorate these areas, thus improving working relationships and increasing the credibility of the department of anesthesiology. If the value of a department is rated highly, this will inevitably (in the long term at least) benefit the department and, for example, facilitate funding for innovative technology, new drugs, etc.

Since surgeons and anesthesiologists work closely on a daily basis, improving relationships between departments will benefit the individuals concerned and, ultimately, can only improve patient care. Moreover, a stress-free work environment and relationships should allow individuals to express their full potential. We suggest this is especially important in the operating room environment where decisions are made rapidly, actions taken are often irreversible and patient safety is paramount. Knowledge of the sources of dissatisfaction (Table III) can lead to different corrective measures. Dissatisfaction may be related to anesthesiologists. The department of anesthesiology will then be responsible for correction in a timely fashion. On the other hand, dissatisfaction may stem from an inappropriate conception/perception by surgeons of what anesthesia services should be. Open discussions to correct erroneous conceptions/perceptions should improve surgeon satisfaction with anesthesia services and relationships among departments. Dissatisfaction may also be related to external factors that may or may not be corrected. Again, corrective action and/or open discussion should improve relationships among departments, the work environment and, ultimately, patient care.

\section{Conclusion}

Evaluation of the level of satisfaction of their different clientele is one of the components of continuous quality improvement in anesthesiology, in order to provide the best possible services. The concept that surgeons are part of the anesthesiologists' clientele may come as a shock for a number of anesthesiologists but is supported by modern literature on CQI. We present a conceptual model that allows surgeon satisfaction to be examined according to characteristics related to anesthesiologists and to characteristics common to both specialties.

Our results show that the SSAS has both internal consistency and construct validity. Reliability and validity of the instrument will have to be tested further, especially with other linguistics groups. The degree of satisfaction/dissatisfaction with anesthesia services presented should be interpreted with caution, bearing in mind that it applies to a general sample of 
surgeons chosen across a provincial population of surgeons and not to a sample taken from a single department of surgery.

\section{Acknowledgments}

The authors would like to acknowledge the outstanding secretarial support of Mrs Céline Charbonneau and Ms Nicole Charbonneau of Accès Secrétariat, Blainville $(\mathrm{Qc})$. We are also grateful to the Editor and the two anonymous reviewers who commented on an earlier draft of this paper.

\section{References}

1 Duncan P. Quality: a job well done! (Editorial) Can J Anaesth 1993; 40: 813-5.

2 Eagle CJ, Davies JM. Current models of "quality" - an introduction for anaesthetists. Can J Anaesth 1993; 40: 851-62.

3 Vitez TS, Macario A. Setting performance standards for an anesthesia department. J Clin Anesth 1998; 10: 166-75.

4 Lee A, Lum ME. Measuring anaesthetic outcomes. Anaesth Intensive Care 1996; 24: 685-93.

5 Iezzoni LI. Risk Adjustment for Measuring Health Care Outcomes. Ann Arbor, Michigan: Health Administration Press, 1994.

6 Golin AK, Ducanis AJ. The Interdisciplinary Team. A Handbook for the Education of Exceptional Children. Rockville, Maryland: Aspen Publication, 1981.

7 Streiner DL, Norman GR Health Measurement Scales. A Practical Guide to their Development and Use. New York, NY: Oxford Medical Publications, 1995.

8 DeVellis RF. Scale Development. Theory and Applications. London, UK: Sage Publications, 1991.

9 Crocker L, Algina J. Introduction to Classical and Modern Test Theory. Montreal: Harcourt Brace Jovanovich College Publishers, 1986.

10 Williams $M A$ Instrument development: always unfinished (Editorial). Res Nurs Health 1989; 12: iii-iv.

\section{Appendix 1}

Surgeon Satisfaction with Anesthesia Services scale (SSAS)

This instrument is designed to measure your level of satisfaction with the services offered by the department of anesthesia. Completion of the questionnaire is important for the continuous quality improvement of the services offered by the anesthesiologists. The questionnaire includes 17 multiple choice questions and 2 open-ended questions. Your answers will be processed confidentially.
If you choose not to answer the questionnaire, would you kindly respond only to the demographic questions preceding the questionnaire and indicate the reason(s) why you chose not to answer. Thank you.

Demographic and professional data

1. What is your age?

2. What is your gender?

3 . What is your surgical speciality?

4. How many years of experience do you have in surgical practice?

5. In a typical week, how many operations do you perform?

6. At your hospital, - There are how many anesthesiologists?

- There are how many surgeons?

7. In a typical week, with how many different anesthesiologists do you work?

Reason(s) for not responding to the questionnaire on satisfaction

Please answer the following questions concerning the anesthesiologists with whom you work. For each question, circle your choice of answer before answering the next question.

\section{The anesthesiologists:}

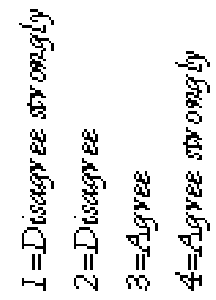

1. maintain patients hemodynamically stable during surgery

$\begin{array}{llll}1 & 2 & 3 & 4\end{array}$

2. communicate with surgeons during surgery

$\begin{array}{llll}1 & 2 & 3 & 4\end{array}$

3. are open to criticism and constructive comments

$\begin{array}{llll}1 & 2 & 3 & 4\end{array}$

4. position patients and induce anesthesia rapidly

$\begin{array}{llll}1 & 2 & 3 & 4\end{array}$

5. encroach on my field of expertise $\quad \begin{array}{llll}1 & 2 & 3 & 4\end{array}$

6. consider my professional opinion $1 \begin{array}{llll}1 & 2 & 3 & 4\end{array}$

7. remain calm during emergencies $\quad \begin{array}{llll}1 & 2 & 3 & 4\end{array}$ 
8. show a passive and indifferent attitude while discussing with surgeons

9. control patients' postoperative pain effectively

10. control mechanical ventilation effectively in the postoperative period l $122 \quad 3 \quad 4$

11.remain sufficiently present in the operating room during surgery to supervise the patient's condition $\begin{array}{lllll}\text { and the devices installed } & 1 & 2 & 3 & 4\end{array}$

12. neglect to update their clinical knowledge/skills

13. show a defensive attitude during discussions

$\begin{array}{llll}1 & 2 & 3 & 4\end{array}$

14. act effectively during emergencies

15. ask too many unnecessary preoperative tests

16. are punctual

$\begin{array}{llll}1 & 2 & 3 & 4\end{array}$

17. are not very likely to adjust their availability according to the surgeon's or patients' needs

The following questions are designed to complement the multiple choice questions. Please detail each of your answers and do not hesitate to add any comments.

A) Are you satisfied with the interactions you have with the anesthesiologists outside the operating room? (eg: during meetings between departments, on the wards, etc.).

B) What do you think would improve the quality of services provided by anesthesiologists to your department of surgery? 